\title{
The Exploitation of Technology in an Islamic Funeral Arrangement
}

\author{
${ }^{1}$ Syarilla Iryani A. Saany, ${ }^{2}$ Asrul Aiman Daod, ${ }^{3}$ Julaily Aida Jusoh, ${ }^{4}$ Engku Ahmad Zaki Bin Engku \\ Alwi, ${ }^{5}$ Ahmad Nazari Mohd Rose ${ }^{6}$ Yousef A.Baker El-Ebiary, ${ }^{7}$ M. Hafiz Yusoff \\ ${ }^{1}$ Assoc. Prof. Dr., Faculty of Informatics and Computing, UniSZA, Malaysia, \\ ${ }^{2}$ Student, Faculty of Informatics and Computing, UniSZA, Malaysia. \\ ${ }^{3}$ Dr., Faculty of Informatics and Computing, UniSZA, Malaysia, \\ ${ }^{4}$ Prof. Dr., Faculty of Contemporary Islamic Studies \\ ${ }^{5}$ Assoc. Prof. Dr. Dean, Faculty of Informatics and Computing, UniSZA University, Malaysia, \\ ${ }^{6}$ Assoc. Prof. Ts. Dr., Faculty of Informatics and Computing, UniSZA University, Malaysia, \\ ${ }^{7}$ Prof. Dato' Dr., Registrar, Albukhary International University, Malaysia, \\ ${ }^{1}$ syarilla@unisza.edu.my, 3julaily@unisza.edu.my ${ }^{4}$ drkuzaki@unisza.edu.my ${ }^{5}$ anm@unisza.edu.my \\ ${ }^{6}$ yousefelebiary@unisza.edu.my, 7 hafiz.yusoff@aiu.edu.my
}

\begin{abstract}
Technologies are keep evolving and growing where almost all activities and services such as in the area of trading, commerce and education can be completed via online. Unfortunately, the funeral arrangement and handling service is still operating in the same process as it is done by our elderly before. Here, the proposed application will help user handling the funeral a lot faster and easier. I-JenzCare is a platform where the service provider and the user can match with one's need on the funeral arrangement service. I-JenzCare is a unique idea because no similar application or system had been developed in related on a Muslim funeral handling yet in Malaysia. This study provides new values to the traditional Islamic funeral arrangement services which has been practiced in the Malay community. I-JenzCare which employs analytical hierarchy process (AHP) technique just requires a medium-end smartphone to keep everything on the best user experience standard. In a nutshell, the system is a handy application for those who needs immediate assistance on funeral handling in Malaysia
\end{abstract}

Keywords

Mobile Application, Analytical Hierarchy Process, Islamic Funeral, Funeral Management in Malaysia, Funeral Arrangement

Article Received: 10 August 2020, Revised: 25 October 2020, Accepted: 18 November 2020

\section{Introduction}

The expression "Islam" signifies accomplishing harmony with God and man, and submitting totally to God in idea, words, convictions and activities. Demise in Islamic culture is adequate and seen as an ordinary piece of life. Muslims see demise as a change starting with one state then onto the next, not an end. The cadaver of a Muslim in Arabic is known as "Janazah". A "Janazah" is characterized as a dead individual [1] and the word is gotten from "janz" which implies something shut [2]. An Arabic language master like Firousabadi additionally said that the word implies something that stays shut and secured. It is gotten from a progression of formations; Janaza-yajnizu-janazatan wa jinazatan [3]. The "burial service" is otherwise called the dead individual who lost his life in this world. Local people additionally allude to the "burial service" as "dead," which is gotten from the Arabic word [4]. Typically, "memorial service" is utilized prior to wearing straightforward internment fabric (kafan). When the body is covered or enveloped by a straightforward piece of fabric (the cover), it is known as the miyat [5].

The interminable inventory of a Muslim, it is the obligation of his family or the various Muslims inside the adjoining neighbourhood organize the entombment administration that manages it as shown in the Islamic Sharia and customs of the area. As in Malaysia, the Muslim Malay people group is unmistakable concerning the arrangement for commemoration administration and chiefs. The Malay
Memorial Service collaboration is orchestrated into two stages. The essential stage is the second ruinous stage and the following stage after death is the chief stage. For this paper, the discussion is just in the second time of the entombment on the load up help.

The posthumous organization period has a couple of stages. They are the start of commemoration administration, washing, stowing away, requesting and internment. The burial service should be washed by Islamic law in the washing of the memorial service (died). The burial service shower will occur after the shower. In the wake of washing and showering, dry the coat with clean towels prior to beginning the covering cycle. As a rule, notwithstanding, three to four people will be connected to genuine clothing and inclusion. Individuals who may wash the expired should be grown-up Muslims, reliable, and of a similar sexual direction as the friendly. For instance, if the consummation is a male, now just men should shower with it, and the exception is for kids, either men or females who are washing and covering. Covering is the pattern of wrapping that happens at a memorial service before a capture closes. The basic size of the cap is examined and this is by refraction over the body through a piece of material that covers the entire body and head. White boards are suggested from an unobtrusive material [6]. It isn't recommended for inordinate use as a cover (Kafan). All assessments may change contingent upon the stature of the memorial service (terminated). Sheet material ought to have no sewing, not silk, outright white texture. It is emphatically connected 
with the way that in the wake of washing and covering the memorial service, it should be covered following the burial service petition.

Intergenerational transmission has not changed the normal practices of arranging and managing funerals that involve local communities. However, the evolvement of the technology offers an opportunity in assisting the funeral arrangement process among the Islamic Malays community. Here, the proposed solution will help family of the deceased handling the funeral a lot faster and easier. I-JenzCare is an online local community platform where the service provider and the user (family of the deceased) can match the arrangement needed on the funeral service. I-JenzCare is a unique idea because no similar application or system had been developed in related on a Muslim funeral handling in Malaysia. This paper introduces new values to the traditional Islamic funeral arrangement services practiced in the Malay community. I-JenzCare which employs analytical hierarchy process technique, just requires a medium-end smartphone to keep everything on the best user experience standard. In a nutshell, the system is a handy application for those who needs immediate assistance on funeral handling in Malaysia.

The remaining of this paper is presented as follows. Section 2 discusses previous work on existing applications similar to this study. In section 3, the methodology and the system framework are discussed followed by section 4 where implementation of this application is presented. Section 5 sums up the study with conclusions and future works.

\section{Previous Work}

Existing applications or websites become good references for this study. In Malaysia, there are only few funeral service application or website, specifically, for Muslims. Some applications that are widely used by millions of users are Pusara Checklist, Muslim Pro, Grab [7].

Pusara Checklist is a Global Positioning Systems (GPS) based cemetery dictionary application. This application capable to store and search cemetery that have been submitted to the system. It can also view others' cemetery search by name. Unfortunately, this application indeed has slow responded even with fast internet connection [8].

Next reviewed application is Muslim Pro application. Muslim Pro is an all-in-one application on Muslim routine prayers guidance [9]. This application has a lot of features where the main features are Quran, Qibla direction and Prayers time with various type of setting. It is a complete application for Muslim basic daily activities guidance.

Another interesting application that has been reviewed is Grab application. Grab is a famous e-hailing application that allows user to arrange transportation and food delivery. Recently, the company also introduced their new features called GrabPay [10]. Even the Muslim Pro and Grab applications seem not related to this study in nature but the features offer in both two applications can be adopted into iJenzCare.

The proposed arrangement, I-JenzCare will incorporate Analytical Hierarchy Process (AHP) innovation and client audit for I-JenzCare to produce a classified memorial service result dependent on client models. These rules are area, rating and administration charges. AHP is an organized strategy that performs complex choice examination, in view of arithmetic and brain science [11]. It is a technique for getting proportions of proportion from the matched examination. Data sources can be gotten from a genuine estimation, for example, value, weight, or sincere belief as sensations of fulfilment and inclination. The AHP calculation included even examination, eigenvector calculation, and proxy request [12]. Self-evaluations are changed over into mathematical qualities and prepared to group every option on a mathematical scale. Table 1 sums up past work on fusing AHP innovation into their examinations.

Table1: Summarization of Previous Works on AHP

\begin{tabular}{|c|c|c|c|}
\hline Author/Year & Method & Explanation & Critics/Limitation \\
\hline $\begin{array}{l}\text { Shuai Li, } \\
\text { Anki Sun, } \\
\text { evaluation } \\
\text { and forecast } \\
\text { Water } \\
\text { Resources } \\
\text { Based on } \\
\text { AHP (2017) } \\
\text { [13] }\end{array}$ & AHP & $\begin{array}{l}\text { To break down } \\
\text { water assets for } \\
\text { research, a } \\
\text { Water } \\
\text { Resources } \\
\text { Assessment } \\
\text { Index (WREI) } \\
\text { model was } \\
\text { made, which } \\
\text { received the } \\
\text { Fuzzy the } \\
\text { Comprehensive } \\
\text { Assessment } \\
\text { (FCE) in light } \\
\text { of } \\
\text { calculation } \\
\text { (AHP). The } \\
\text { auxiliary } \\
\text { elements were } \\
\text { disregarded } \\
\text { and henceforth } \\
\text { the various } \\
\text { leveled apd } \\
\text { approach put } \\
\text { the the } \\
\text { fundamental } \\
\text { elements as } \\
\text { indicated by } \\
\text { the division, } \\
\text { and a three- } \\
\text { layer structure. } \\
\text { The high level } \\
\text { is WREI. AHP } \\
\text { was utilized for } \\
\text { the weight was } \\
\text { resolved first, } \\
\text { at that point a } \\
\text { mysterious } \\
\text { judgment was } \\
\text { utilized to pass } \\
\text { judgment on } \\
\text { the objective. }\end{array}$ & $\begin{array}{l}\text { The given } \\
\text { example is not } \\
\text { related from } \\
\text { objective of this } \\
\text { system. } \\
\text { Using } \\
\text { technique which } \\
\text { is, (AHP) and } \\
\text { fuzzy } \\
\text { comprehensive } \\
\text { evaluation (FCE). } \\
\text { It is too much for } \\
\text { the system. }\end{array}$ \\
\hline
\end{tabular}




\begin{tabular}{|c|c|c|c|}
\hline $\begin{array}{l}\text { Lam Wing } \\
\text { Seo, Ranjit } \\
\text { Singh A/L } \\
\text { Bishan } \\
\text { Singh, Lam } \\
\text { Wing Ho, } \\
\text { Liu Kah Fei, } \\
\text { Pilot Study } \\
\text { on } \\
\text { Preference } \\
\text { for } \\
\text { Supermarkets } \\
\text { with } \\
\text { Analytical } \\
\text { Hierarchy } \\
\text { Process } \\
\text { Model } \\
\text { (2018) (Lam } \\
\text { Wing Seo, } \\
\text { 2018), [14], }\end{array}$ & AHP & $\begin{array}{l}\text { To choose the } \\
\text { most favoured } \\
\text { grocery store } \\
\text { among Jaya } \\
\text { Grocer, } \\
\text { AEON, Tesco, } \\
\text { Giant and } \\
\text { Econsave by } \\
\text { college } \\
\text { understudies in } \\
\text { Malaysia with } \\
\text { (AHP) Model. } \\
\text { (AHP) is a } \\
\text { model it was } \\
\text { acquainted } \\
\text { with study the } \\
\text { attributes that } \\
\text { are identified } \\
\text { with the } \\
\text { understudy's } \\
\text { propensity to } \\
\text { visit or shop in } \\
\text { certain general } \\
\text { stores.. }\end{array}$ & This technique apt \\
\hline
\end{tabular}

\section{System Design And Implementation}

Applications are intended to be adaptable, simple to utilize, convenient, and to help dynamic data. The application is created utilizing the Ionic structure (HTML, TS, CSS) and MySQL for online data set stockpiling [15]. Figure 1 portrays the system of this examination.

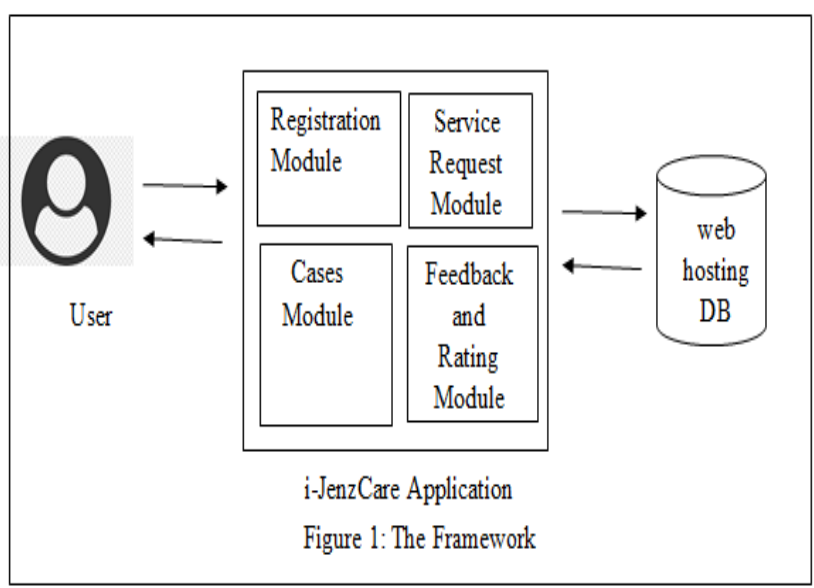

Figure 1: The Framework

i-JenzCare application acts as a platform between Muslim users and funeral handlers on Islamic funeral management. Funeral handlers will be called as service provider in future reference. This application has four modules as depicts in Figure 1. Service providers will register their particulars in i-JenzCare application which will become their profiles.

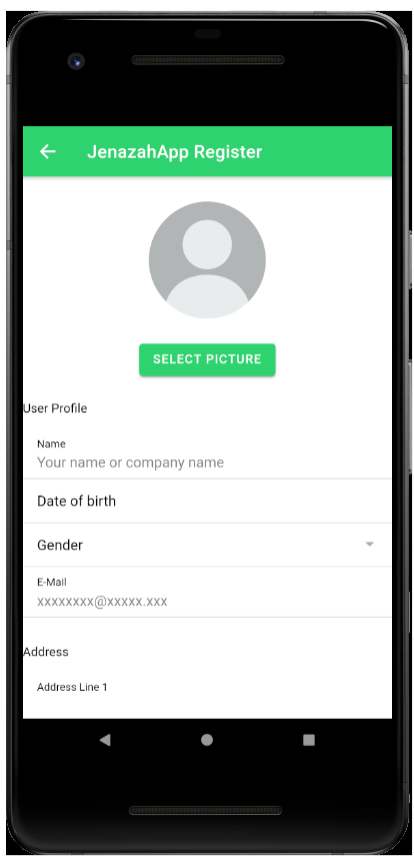

Figure 2: Registration

Users can request service on funeral arrangement and management based on proximity of the service providers. The service offered normally on bathing, shrouding, praying and burial of the jenazah. These also include all the preparation needed in handling the funeral. However, user may also itemize the service requested. Upon requesting the service, i-JenzCare will rank and list the service providers either by proximity or user reviewed. Figure 2 shows that the requested service request by the user has been agreed to be handled by the chosen service provider.

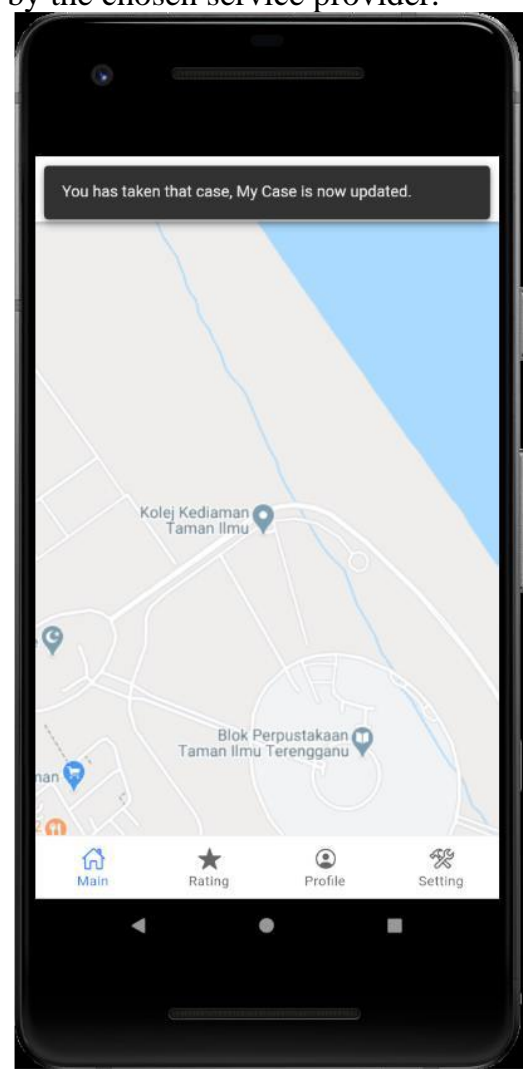

Figure 2: Service Requested Status 
After completing all the requested funeral services, the service provider will update remarks on the completed service. This will be processed by cases module. Cases module records all the services handled by the service provider. Based on the service given, users are encouraged to write or give feedback via i-JenzCare application. This rating and feedback will use to rate the service providers.

\section{Conclusion}

This study presents the development of the application that focuses on the Islamic funeral arrangement with the aid of technology. Through this application, it can stream the information on the funeral service offered within the community. I-JenzCare application is viewed as an aid to the deceased family to arrange and manage the jenazah as soon as possible after his death. For future work, i-JenzCare application plans to integrate with another module that relates with Islamic law on the division of the deceased's property heredity known as faraid.

\section{References}

[1] Belal Alifan, Mokhairi Makhtar, Yousef El-Ebiary. "Propose Model for Consumers' Perceptions and Acceptance of e-Health Systems and Services in Jordan" Vol. 68, Editor's Issues, Oct. 2020, pp. 1-10, IJETT, doi: 10.14445/22315381/CATI3P201.

[2] Yamin, M., Basahel, A.M, and Abi Sen, A.A (2018). Group the board utilizing remote and versatile innovations. Remote Communications and Mobile Computing, 2018.

[3] Kihara, J. N. (2013). Innovation strategies adopted by funeral homes in Nairobi County, Kenya (Doctoral dissertation, University of Nairobi).

[4] Bunruamkaew, K. (1 March, 2012). How to do AHP analysis in Excel. Retrieved from SlideShare: https://www.slideshare.net/rabbittrix/howto-do-ahp-analysis-in-excel

[5] Chothia, Y. (2010). Home: Muslim Funeral Service. Retrieved from Muslim Funeral Service: https://www.mfs.asn.au/

[6] Ummu Hani Abas, A.Ghani Bin Md Din, M. Syauqi Arshad, Faridah Isa Binawae, Harliza B. H., Yousef A.Baker El-Ebiary., "The Usage of Google Translator Apps in Translation of the Arabic-Language Book into Indonesia and Malaysia: Comparative Review",(JCR). 2020; 7(15): 669-674, doi: 10.31838/jcr.07.15.37

[7] Fudzin, A. (2019). Analytical hierarchy process application of body in white modular sub-assembly for automotive manufacturing in Malaysia - A case study. Retrieved from IOP Science: https://iopscience.iop.org/article/10.1088/1 757-899X/469/1/012004/pdf

[8] Yousef El-Ebiary, Nahg Abdul Majid Alawi. "The Role of Computer Based Accounting Information System in Supporting Top-Management Decisions" Vol. 68, Editor's Issues, Oct. 2020, pp. 114-119, IJETT, doi: 10.14445/22315381/CATI3P219.

[9] Shuai Li, A. S. (2017). Evaluation and Prediction of Water Resources Based on AHP. Retrieved from IOP Science: https://iopscience.iop.org/article/10.1088/1 742-6596/51/1/012017/pdf

[10] Yousef A.Baker El-Ebiary, Samer Bamansoor, Waheeb Abu-Ulbeh, Wan Mohd Amir, Syarilla Iryani A. Saany, M. Hafiz Yusoff. "Using Interval Manager Mobile Application in Saving Time and Cost" Vol. 68, Editor's Issues, Oct. 2020, pp. 82-85, IJETT, Doi: 10.14445/22315381/CATI1P214.

[11] W. M. Amir Fazamin W. Hamzah, Waheeb Abu-Ulbeh, Najeeb Abbas AlSammarraie, Yousef A.Baker El-Ebiary, M. Hafiz Yusoff, Syarilla Iryani A. Saany, Azliza Yacob. "The Integration of Learning Management Systems with PLE - a Review Paper" Vol. 68, Editor's Issues, Oct. 2020, pp. 94-96, IJETT, doi: 10.14445/22315381/CATI1P217.

[12] Russo, J. P. (1998). The humanities in a technological society. Humanitas, 11(1), $14-41$.

[13] M. Hamed M. Said, Rabie I. M. H., Shaaban A. Hameed Refae M., Shehata H. M. El Sheikh, Sabah Ayesh Aljohani, Yousef A.Baker El-Ebiary. "A Contemporary Technical Vision of the Characteristics of Islamic Systems". JCR. 
2020; $\quad 7(16): \quad 1133-1140$.

doi:10.31838/jcr.07.16.144.,

[14] Salleh, Muhammad Yusri \& zahirwan, mohd \& Hassan, Paiz \& yahaya, faridah. (2017). Funeral Management in the Malay World: Local Knowledge and Practices.

[15] Yusef, M.Y. , Abdul Rahim, R. A, Yahya, F, Hassa, and B. Memorial service Management in the Malay World: Local Knowledge and Practices. J Appl Environ Biol Sci, 7 (IS), 72-77. 